\title{
Temperature Effects on Lily Development Rate and Morphology from the Visible Bud Stage until Anthesis
}

\author{
John E. Erwin ${ }^{1}$ and Royal D. Heins \\ Department of Horticulture, Michigan State University, East Lansing, MI 48824-1112 \\ Additional index words. Lilium longiflorum, thermomorphogenesis, DIF, degree day, thermoperiodism, stem elongation, \\ plant development, flower bud abortion, plant height, inflorescence development

\begin{abstract}
Day (DT) and night temperatures (NT) influenced Lilium longiflorum Thunb. 'Nellie White' stem elongation and development rate from the visible bud stage (VB) until anthesis. Plant height increase after VB was a function of the difference (DIF) between DT and NT (DT-NT). Plant height increased $90 \%$ as DIF increased from - 16 to 16C. A cubic model described bud development rate as a function of temperature from 14 to $30 \mathrm{C}$. A linear model adequately described bud development rate as a function of average daily temperature from 14 to $21 \mathrm{C}$. Based on the linear model, bud development rate increased 0.05 per day for each $1 \mathrm{C}$ increase in average daily temperature. The as 3.5C.
\end{abstract} \\ base temperature for bud development, i.e., the temperature at which bud development rate was 0 , was calculated
}

Greenhouse forcing of vernalized Easter lilies is commonly divided into three phases: I) placement of vernalized bulbs in the greenhouse to flower initiation, II) flower initiation to VB, and III) VB to anthesis (De Hertogh and Wilkins, 1971). Plant morphological development differs during each of the forcing phases (De Hertogh and Wilkins, 1971). Growth during phase I is vegetative and consists of stem elongation and leaf expansion. Flower initiation, leaf expansion, and stem elongation occur during phase II. Inflorescence expansion and stem elongation occur during phase III.

Lily responses to temperature during phase III differed from those during phases I and II (Wang and Roberts, 1983). Lily development rate, quantified as days to unfold a leaf, is a decreasing linear function of average daily temperature between 14 and 30C during phases I and II (Karlsson et al., 1988). Lily development rate during phase III is a nonlinear function of temperature (Healy and Wilkins, 1984). The effect of temperature on the rate of lily development decreases as DT and/or NT increase during phase III (Roh and Wilkins, 1973; Healy and Wilkins, 1984).

Easter lily morphological development is thermomorphogenie. For instance, internode length increases as the DIF between DT and NT increases (Erwin et al., 1989). In addition, leaf orientation, leaf length, and flower length are also influenced by diurnal changes in temperature.

Quantification of Easter lily responses to temperature is useful to Easter lily growers. Selection of the proper average daily temperature is critical to achieve a desired rate of plant development so plants flower for a desired marketing date. Improper selection of temperatures during phases II and III may result in incorrect crop timing, flower bud abortion (Roh and Wilkins, 1973), and/or excessively tall or short plants at anthesis (Erwin et al., 1989). Karlsson et al. (1988) developed a mathematical

\footnotetext{
Received for publication 4 Dec. 1989. Mich. Agr. Expt. Sta. no. 12677. We appreciate the assistance of Cathey Fredenburg, James Eppink, and Sharon Strand during this project. Lily bulbs were donated by the Pacific Bulb Grower's Association. This project was funded in part by a grant from the Fred C. Gloeckner Foundation and The American Floral Endowment. The cost of publishing this paper was defrayed in part by the payment of page charges. Under postal regulations, this paper therefore must be hereby marked advertisement solely to indicate this fact.

'Present address: Horticultural Science, University of Minnesota, 1970 Folwell Ave., Saint Paul, MN 55108.
}

function relating the rate of lily leaf unfolding to average daily temperature during phase II. Similarly, Erwin et al. (1989) determined the functional relationships for the effects of DT and NT on stem elongation and leaf orientation during phase II. Healy and Wilkins (1984) developed functional relationships between lily bud length and the time to flower of plants grown with constant DT and NT during phase III. The functional relationships describing the rate of lily development and stem elongation for lily plants grown at different DT and NT during phase III have not been determined.

The objective of this research was to develop mathematical functions relating the rate of Easter lily development and stem elongation to DT and NT during phase III.

\section{Materials and Methods}

Easter lily bulbs 17.7 to $20.3 \mathrm{~cm}$ in circumference were planted in $15.2-\mathrm{cm}(2,570 \mathrm{ml})$ plastic pots on 28 Oct. 1985 , in a soilless medium consisting of equal parts of sphagnum peat, perlite, and vermiculite. Potted bulbs were placed in a greenhouse for 2 weeks where air temperature was adjusted to maintain a medium temperature of $17 \pm 1 \mathrm{C}$ to encourage root development. Plants were then vernalized for 6 weeks at 5C, after which all plants were placed in a glasshouse under natural photoperiodic conditions with constant 20C DT and NT setpoints. Upon shoot emergence, plants received a long-day treatment for 7 days, consisting of the natural photoperiod ( $\approx 9 \mathrm{hr} 15 \mathrm{~min}$ ) plus night interruption lighting from 2200 to $0200 \mathrm{HR}$ delivered with incandescent lamps at a $2 \mu \mathrm{mol} \cdot \mathrm{s}^{-1} \cdot \mathrm{m}^{-2}(400$ to $700 \mathrm{~nm}$ wavelength). Plants were returned to natural photoperiodic conditions after the long-day treatment.

Time of flower initiation was established by terminal-shoot dissections every 3 days on five randomly selected plants starting 13 Jan. 1986. Flower initiation was defined as the first visible differentiation of the vegetative meristem into a reproductive meristem (De Hertogh et al., 1976) (Fig. 2C). Flower initiation was observed on $100 \%$ of the sample on 22 Jan.

Plants were then selected for uniformity based on plant height and leaf number and moved to greenhouses maintained at 14 , $18,22,26$, or $30 \mathrm{C}$. Actual average temperatures during the

Abbreviations: DT, day temperature; DIF, difference between day temperature and night temperature NT, night temperature; VB, visible bud stage. 
experiment did not vary by more than $1.8 \mathrm{C}$ from the desired temperature setpoints. Plants were moved among greenhouses at 0800 and $1800 \mathrm{HR}$ each day to yield a total of $25 \mathrm{DT} / \mathrm{NT}$ treatment combinations. Each temperature treatment, had five single-plant replicates (total of 125 plants). Movement of plants required $\approx 30 \mathrm{~min}$. An opaque curtain was pulled over the plants at $1800 \mathrm{HR}$ and was retracted just before $0800 \mathrm{HR}$ to provide a 14-hr scotoperiod to parallel the night temperature treatment. Plants were spaced at 11 plants $/ \mathrm{m}^{2}$.

Data were collected on the date and plant height at VB and anthesis. Plant height was defined as the height of the plant from the soil line to the tip of the uppermost bud.

Analysis of variance (ANOVA) was conducted using the ANOVA procedure of The Statistical Package Of The Social Sciences (Nie, 1975). Regression analysis of the data was conducted using the 'All Possible Subsets Regression (P9R)' and the 'Stepwise Regression (P2R)' subroutines of the 'Biomedical Statistical Software Package' (Dixon, 1983). Models were selected based on evaluation of residuals, $r^{2}$, and Mallow's $\mathrm{C}_{\mathrm{P}}$ (Draper and Smith, 1981). Allparameters selected in the models were significant at $P=0.05$.

\section{Results and Discussion}

Change in height from VB until anthesis. Change in plant height after VB was a function of DIF between DT and NT (i.e., DT-NT). Plant elongation after VB increased from 14.2 to $27.0 \mathrm{~cm}$ as DIF increased from -16 to $16 \mathrm{C}$ (Fig. 1). The relationship between DIF and stem elongation after VB is consistent with previous lily research that showed a greater effect of DIF on internode elongation during phase II than absolute DT and/or NT (Erwin et al., 1989). Kohl (1958) showed that plant heights were similar on lilies grown at a constant 21.1, 15.5 , or $10 \mathrm{C}$ (0 DIF), as expected if DIF controls elongation

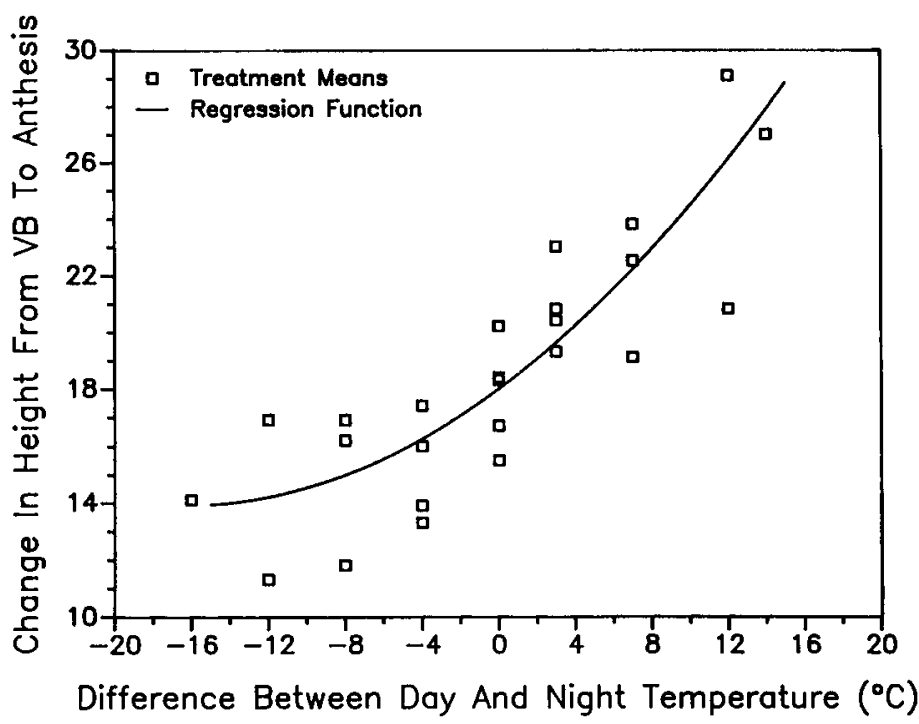

Fig. 1. Relationship between Lilium longiflorum CV. Nellie White height increase during phase III and the difference between the DT and NT (DT-NT). Squares represent the mean change in plant height after visible bud for each temperature treatment as determined from five plants. The solid line represents the function: Height increase after visible bud $=(0.496946 * \mathrm{DIF})+\left(0.150561 * \mathrm{DIF}^{2}\right)+18.01$ $\left(r^{2}=0.77\right)$. and not absolute temperatures between 10 and 30C. Roh and Wilkins (1973) reported that stem elongation after VB was only affected by DT >21.1C. Regression of treatment means reported by Roh and Wilkins with DIF as the independent variable and plant height at anthesis as the dependent variable resulted in a model with an $r^{2}$ of 0.63 . This model likely would have had a higher $r^{2}$ if the regression had been based on the change in height after VB only, as treatments were only initiated following VB and a significant amount of stem elongation had occurred before VB. These data, however, were not reported. Our results contradict the results of Smith and Langhans (1962), who stated that DT and NT did not affect height during developmental phases II and III.

Development rate from VB until anthesis. The time from VB to anthesis decreased as either DT or NT increased from 14 to 26C (Table 1). The minimum time from VB to anthesis was 26 days when plants were grown at constant 26C. These data are similar to results of Roh and Wilkins (1973), who reported a minimum time of 24 days with 'Ace' Easter lily at a constant 32C.

Lily flower bud development rate was a quadratic function of temperature when DT and NT were held constant (Fig. 2). Maximum flower development rate was near 26C. The maximum near 26C is similar to that of wheat (Friend et al., 1962) and maize (Aim et al., 1988; Tollenaar et al., 1979; Warrington and Kanemasu, 1983), where the maximum leaf unfolding rate occurred between 25 and 30C. The temperature optimum for flower bud development is lower, however, than for lily leaf unfolding, which is > 30C (Karlsson et al., 1988).

When DT and NT were not identical, daily flower bud development rate was the mathematical sum of the hourly flower bud development rates at the temperatures at which plants were grown. Figure 2 shows straight lines connecting the development rate at $30 \mathrm{DT} / 30 \mathrm{NT}$ with those at $14 \mathrm{DT} / 14 \mathrm{NT}, 18 \mathrm{DT} /$ 18 NT, 22 DT/22 NT, and 26 DT/26 NT. These lines represent the expected flower development rates for all average daily temperatures created by the DT and NT combinations of the temperatures connected by a line. Data points of actual development rates of plants from treatments with temperature combinations associated with the lines show that actual rates of development are close to predicted rates.

The prediction model for development rate was based on 10hr day and a 14-hr night period. This model can be modified for any length of day;

$$
\begin{aligned}
\text { Daily rate }= & \mathrm{b}_{1}+\mathrm{b}_{2} *\left[\left(\mathrm{HDT}^{*} \mathrm{DT}\right)+\left(\mathrm{HNT}^{* N T}\right)\right] / 24 \\
& +\mathrm{b}_{3}{ }^{*} \mathrm{HDT}^{*} \mathrm{DT}^{3} / 10+\mathrm{b}_{4}{ }^{*} \mathrm{HNT}^{*} \mathrm{NT}^{3} / 14
\end{aligned}
$$

Table 1. The influence of DT and NT on the number of days from

\begin{tabular}{|c|c|c|c|c|c|c|}
\hline \multirow{2}{*}{$\mathrm{NT}\left({ }^{\circ} \mathrm{C}\right)$} & & \multicolumn{5}{|c|}{$\mathrm{DT}\left({ }^{\circ} \mathrm{C}\right)$} \\
\hline & & 14 & 18 & 22 & 26 & 30 \\
\hline \multirow{2}{*}{\multicolumn{2}{|c|}{14}} & \multicolumn{5}{|c|}{ Days } \\
\hline & & $41.5^{x}$ & 38.4 & 31.0 & 31.2 & 32.0 \\
\hline 18 & & 38.6 & 33.2 & 31.0 & 29.8 & 29.3 \\
\hline 22 & & 34.8 & 30.8 & 27.5 & 26.8 & 26.4 \\
\hline 26 & & 32.8 & 30.8 & 27.2 & 25.6 & 25.6 \\
\hline 30 & & 31.2 & 28.8 & 26.4 & 26.2 & 25.7 \\
\hline DT & & & NT & & & \\
\hline Linear & $* * *$ & & Linear & & $* * *$ & \\
\hline Quadratic & $* * *$ & & Quadr & & $* * *$ & \\
\hline Cubic & NS & & Cubic & & NS & \\
\hline
\end{tabular}
VB to open flower in Lilium longiflorum CV. Nellie White.

${ }^{2}$ Numerals represent treatment means.

${ }^{\text {Ns, }{ }^{* * *}}$ Nonsignificant or significant at $P=0.001$. 


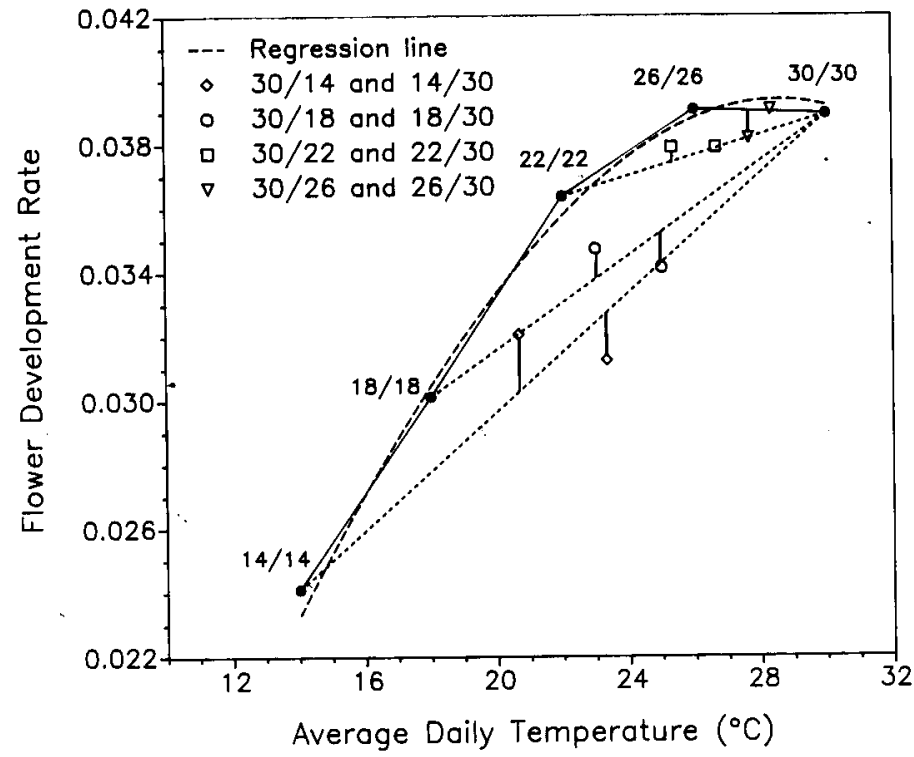

Fig. 2. Lilium longiflorum 'Nellie White' bud development rate per hour as a function of temperature. The regression line $\left(--_{-}\right)$is based on the function: Daily rate $=-0.103658 \mathrm{E}-1+0.2615 \mathrm{E}-2$ * [(HDT * DT) + (HNT * NT) $] / 24-0.408527 \mathrm{E}-6 / 10 *$ HDT * $\mathrm{DT}^{3}-0.66292 \mathrm{E}-6 / 14 *$ HNT $* \mathrm{NT}^{3}\left(r^{2}=0.96\right)$. HDT and HNT are hours of day and night temperature, respectively. The bars associated with data points (-) represent deviation between observed and expected flower development rate.

where $b_{1}, b_{2}, b_{3}$, and $b_{4}$ are parameter coefficients. HDT and HNT are hours of day and night, respectively.

The model can be further modified to directly calculate hourly development rate at a specific temperature;

$$
\text { Hourly rate }=b_{1} / 24+b_{2}^{*} T^{3} / 24+\left(b_{3}+b_{4}\right)^{*} T^{3} / 24
$$

where $\mathrm{T}$ is the hourly temperature.

When either DT or NT does not exceed 22C, daily flower development rate can be approximated by a linear function based on average daily temperature (ADT):

$$
\text { Daily rate }=-0.740904 \mathrm{E}-02+(0.209036 \mathrm{E}-02 * \text { ADT }) .[3]
$$

A linear ADT model can be used because development rate is nearly linear in the 14 to $22 \mathrm{C}$ temperature range (Fig. 2). When development rate is a linear function of ADT, a degreeday model can be used (Karlsson et al., 1988). From Eq. [3], 478 degree days are required above a base temperature of $3.5 \mathrm{C}$ for lily flower bud development from VB to flowering. This base temperature calculated for flower bud development is similar to the $\mathrm{IC}$ base temperature for lily leaf unfolding (Karlsson et al., 1988).

\section{Literature Cited}

Aim, D.M., D.R. Pike, J.D. Hesketh, and E.W. Stoller. 1988. Leaf area development in some crop and weed species. Biotronics 17:29_ 39.

De Hertogh, A.A. and H.F. Wilkins. 1971. The forcing of northwestgrown 'Ace' and 'Nellie White' Easter lilies. Flor. Rev 149:29-31, 57, 104-111.

De Hertogh, A.A. H.P. Rasmussen, and N. Blakely. 1976. Morphological changes and factors influencing shoot apex development of Lilium longiflorum Thunb. during forcing. J. Amer. Soc. Hort. Sci. 101:463-471.

Dixon, W.J. 1983. BMDP statistical software. Univ. of Calif. Press., Berkely. p. 251-277.

Draper, N.R. and H. Smith. 1981. Applied regression analysis. 2nd ed. Wiley, New York. p. 294-313.

Erwin, J.E., R.D. Heins, and M.G. Karlsson. 1989. Thermomorphogenesis in Lilium longiflorum Thunb. Amer. J. Bot. 76:47-52.

Friend, D.J.C., V.A. Helson, and J.E. Fisher. 1962. Leaf growth in marquis wheat, as regulated by temperature, light intensity, and daylength. Can. J. Bot. 40:1299-1311.

Healy, W.E. and H.F. Wilkins. 1984. Temperature effects on 'Nellie White' flower bud development. HortScience 19:843-844.

Karlsson, M.G., R.D. Heins, and J.E. Erwin. 1988. Quantifying temperature controlled leaf unfolding rates in Lilium longiflorum Thunb. 'Nellie White'. J. Amer. Soc. Hort. Sci. 113:70-74.

Kohl, H. 1958. Effects of temperature variation on forced Lilium longiflorum var. 'Ace'. J. Amer. Soc. Hort. Sci. 72:477-480.

Nie, N.H. 1975. SPSS: Statistical package for the social sciences. version 10.00. McGraw-Hill, New York. p. 398-433.

Roh, S.M. and H.F. Wilkins. 1973. Influence of temperature on the development of flower buds from the visible bud stage to anthesis of Lilium longiflorum Thunb. cv. 'Ace'. HortScience 8:129-130.

Smith, D. and R. Langhans. 1962. The influence of day and night temperatures on the growth and flowering of the Easter lily (Lilium longiflorum Thunb. var. 'Croft'). J. Amer. Soc. Hort. Sci. 80:593598.

Tollenaar, M., T.B. Daynard, and R.B. Hunter. 1979. Effect of temperature on rate of leaf appearance and flowering date in maize. Crop Sci. 19:363-366.

Wang, Y.T. and A.N. Roberts. 1983. Influence of air and soil temperature on the growth and development of Lilium longiflorum Thunb. during different growth phases. J. Amer. Soc. Hort. Sci. 108:810815 .

Warrington, I.J. and E.T. Kanemasu. 1983. Corn growth response to temperature and photoperiod. II. Leaf initiation and leaf appearance rates. Agron. J. 75:755-761. 